\title{
Polo Yaka T-Shirt Üretim Bandinda Farkli Makine Türlerine Göre Genel Ekipman Verimliliğinin Hesaplanması
}

\author{
Mehmet Küçük ${ }^{*}$, Meral İşler², \\ 1*Ege Üniversitesi, Mühendislik Fakültesi, Tekstil Mühendisliği Bölümü, İzmir, Turkey,(ORCID: 0000-0002-0017-5762), mehmet.kucuk@ ege.edu.tr \\ ${ }^{2 *}$ Selçuk Üniversitesi, Mimarlık ve Tasarım Fakültesi, Moda Tasarımı Bölümü, Konya, Turkey, (ORCID: 0000-0002-9654-4664), meralisler@ selcuk.edu.tr
}

(DOI: 10.31590/ejosat.1039304)

ATIF/REFERENCE: Küçük, M., \& İşler, M. (2021). Polo Yaka T-Shirt Üretim Bandinda Farkli Makine Türlerine Göre Genel Ekipman Verimliliğinin Hesaplanmasi. European Journal of Science and Technology, (32), 891-896.

\section{$\ddot{O} \mathbf{z}$}

Günümüzün gelişen teknolojisinin getirdiği rekabet ortamı ve zorlaşan piyasa koşullarında mücadele etmek gün geçtikçe zorlaşmaktadır. Bu durum hem teknolojiye ayak uydurup çağın gerisinde kalmamayı hem de elindeki makine ve ekipmanı en verimli şekilde kullanmayı gerektirmektedir. İşletme bünyesindeki makine, teçhizat ve ekipmanı en etkin ve verimli şekilde kullanmak genel performansı artırdığı gibi, işletme içerisindeki maliyetleri de düşürmektedir. Bütüncül bir yaklaşım olan "OEE- Genel Ekipman Verimliliği” (Overall Equipment Efficiency) takibi bu verimlilik ölçüm yöntemlerinden biridir. Genel ekipman verimliliği girdilerin ne derece verimli kullanıldığını gösterir ve üretim sırasındaki kayıpları (arızalar, hatalar, vb.) minimize etmeyi amaçlamaktadır. Bu noktadan yola çıkılarak bu çalışmanın amacı, kullanılan girdilerin ve üretim süreçlerinin üretim hattındaki etkinliğe ve verimliliğe etkisini genel ekipman verimliliği yöntemi ile üretim hattından veriler toplayarak tespit etmektir. Toplanan veriler kullanılarak bir polo yaka t-shirt hattının öncelikle genel, ayrıca da makine bazında (düz, overlok, otomat vb.)kullanılabilirlik, performans, kalite ve OEE değerleri hesaplanmıştır. Araştırma sonuçları işletmenin performans, kalite ve kullanılabilirlik parametreleri iyi sonuçlar vermesine rağmen genel ekipman verimliliği değerlerinin Dünya Klasmanı değerlerinin altında kaldığı tespit edilmiştir.

Anahtar Kelimeler: Verimlilik, OEE, Hazır Giyim Üretimi, Polo Yaka T-shirt, Ekipman Verimliliği

\section{Computation of General Equipment Efficiency According to Different Machine Types in Polo Neck T-Shirt Production Line}

\begin{abstract}
Due to today's developing technology and difficult market conditions, companies have to struggle to stand out in this ecosystem. This situation requires keeping up with technology, not staying behind the era, and using the machinery and equipment most efficiently. Using the machinery and equipment within the business most effectively and efficiently increases overall performance and reduces the businesses' costs. This situation can be succeeded possibly by monitoring "OEE (Overall Equipment Efficiency). Based on this point, this study aims to determine the effect of the used sewing machines on the production line's efficiency and productivity by using the general equipment efficiency method. Availability, performance, quality, and OEE values were calculated on the basis of general evaluation and also on the machine-wise (lockstitch, overlock, automat, etc.). The results of the research showed that although the performance, quality and usability parameters gave good results, the overall equipment efficiency values remained below the World Class values.
\end{abstract}

Keywords: Efficiency, OEE, Apparel Production, Polo T-shirt, Equipment Efficiency.

\footnotetext{
*Sorumlu Yazar: Ege Üniversitesi, Mühendislik Fakültesi, Tekstil Mühendisliği Bölümü, İzmir, Turkey, mehmet.kucuk@ege.edu.tr
} 


\section{Giriş}

Verimlilik, toplumsal ve ekonomik gelişimin temel taşlarından birini oluştururken, işletmelerin de rekabet kabiliyetinin artırılmasında önemli rol oynamaktadır. Tanımsal olarak verimlilik, üretilen mal ve hizmetlerin miktar, tutar ve kalitesi ile bunları üretmek için kullanılan kaynaklar arasındaki ilişki olarak ifade edilir[1]. Ticari piyasada aktif olarak faaliyet gösteren birçok işletmenin uzun ömürlü olabilmesi verimliliği ön planda tutarak, düşük maliyet ve mümkün derecede yüksek kaliteyle üretim yapma zorunluluğundan geçmektedir. Bunun yanı sıra müşteri beklentilerine doğru ve istenen sürede karşılık verebilmek de bu doğrultuda olmazsa olmazlardandır. Kalitede rekabet, beraberinde hizmet kalitesi ve güvenilirliğini de gerektirirken, fiyat rekabeti ise işletmelerin maliyetlere odaklanmasını sağlamaktadır. Bu durum da zamanı ve insan kaynaklarını etkin kullanmak demektir. İşletme içerisindeki performanslar bu birimlerin (çalışan, makine vb.) sahip oldukları verimlilik değerleriyle karşılaştırılır.

Üretim sürecinde elde edilen ürünlerin, bu ürünü üretmek için tüketilen kaynaklara oranlanması verimliliğin tanımı olarak gösterilmiştir. Verimlilik, üretimin başından tüketimin son aşamasına kadar kaynakların kullanımı ile ilgili bir süreç içerisinde her zaman geçerlidir ve ekonomik anlamda rasyonel bir yolun izlenmesini gerektirmektedir[2].

Üretim faktörlerinin (insan, makine ve malzeme) kullanımına ve elde edilen çıktılara bağlı olarak hesaplanan ve bir karşılaştırma terimi olan verimliliğin yanı sıra, işletme içerisinde veya işletmeler arasında üretim faktörlerinin kullanım etkinlikleri de bir başka karşılaştırma terimi olarak kullanılabilmektedir. Yalın üretim uygulamalarından biri olan OEE, üretim faktörlerinin etkinliğinin gözlendiği ve geliştirildiği bir yoldur. OEE, üretim verimliliği kayıplarının kaynaklarını üç ana kategoriye yerleştirerek, bunları işlemin nerede olduğunu ve nasıl gelişeceğini ölçmek için ölçüm altyapısı sağlar[3].

Genel ekipman verimliliği toplam üretken bakımla birlikte ya da bağımsız olarak araştırmacıların dikkatini çeken bir konudur. İlgili literatür incelendiğinde imalat sistemlerinde genel ekipman verimliliğiyle ilgili bir çok çalışma bulunmaktadır. 2012 yılında Karim ve Rahman tarafindan yapılan bir araştırmada konfeksiyon sektörü ele alınmış, OEE ve verimlilik başlığ altında bir vaka çalışması yapılmıştır. Çalışmanın sonunda performansı iyileştirmeye yönelik bazı önerilerde bulunulmuştur[4]. Senthilkumar ve Thavaraj tarafindan 2014 yılında yapılan bir çalışmada, toplam kalite yönetimi uygulamaları için bir tişört üretim hattının 5 farklı dikiş makinesi seçilmiştir. $\mathrm{Bu}$ makinelerin performans seviyeleri toplam kalite yönetimi uygulamaları öncesi ve sonrasında analiz edilmiştir[5]. Aminuddin ve diğerleri tarafindan 2015 yılında yapılan bir çalışmada, OEE'nin imalat sanayinde uygulanması ve kullanımı ile ilgili yönetsel konular incelenmiştir. $\mathrm{Bu}$ amaçla beş farklı hipotez ve dört soru hazırlanmış ve formüle edilmiştir. Veriler, dünya çapında 139 imalat kuruluşu tarafindan yanıtlanan bir anket anketi aracılığıyla toplanmıştır[6]. 2015 yılında Sivakumar ve diğerleri tarafından yapılan bir çalışmada, bir kumaş firmasının mevcut durumu toplam verimlilik modeli ve bulanık kümeler yöntemleri ile incelenmiştir. Bu kapsamda mevcut durumdaki başabaş noktaları verimlilik ve kalite iyileştirmeleri için analiz edilmiştir. Bu çalışmanın sonunda, bulanık sistemler ile verimlilik ve kalite boyutları değerlendirildikten sonra, şirket içindeki risk noktaları belirlenmiştir[7]. Tomar ve Bhuneriya, 2016 yılında Hintli bir şirketin OEE durumu hakkında bir çalışma hazırlamışlardır. Bu çalışmada, bu şirketin mevcut durumu OEE ile kontrol edilmiş, daha sonra araştırmacılar tarafından gözden geçirilmiş ve gerçek zamanlı Genel ekipman etkinliği ölçülerek şirket yönetimine gösterilmiştir[8]. Ahmet vd. 2018 y1lında OEE hakkında bir makale hazırlanmıştır ve bu çalışma, bir iplik fabrikasında bir ring iplik makinesinin iyileştirilmesi amacıyla incelemeler yapılmıştır. OEE uygulamasından sonra ring iplik makinesindeki kayıp süreler azaltılmış ve verimlilik artırılmıştır [9]. Shakil ve Parvez 2018'de, bir firmanın üretim sürecini ele aldıkları çalışmanın amacı, sürecin OEE'sini iyileştirmek için akışı ve süreçteki parti boyutlarının analiz edilmesidir. Sürecin mevcut durumu analiz edildikten sonra, yazarlar daha iyi bir akış elde etmek için yeni bir düzen önermişlerdir[10]. Yazdi ve diğerleri tarafından 2018 yılında yapılan çalışmada amaç, kontrol mimarisi olarak etmen tabanlı bir algoritma kullanarak malzeme dağıtımı için sürdürülebilir, akıllı bir malzeme taşıma sisteminin yeni bir uygulamasını oluşturmaktır[11].

$\mathrm{Bu}$ kapsamda bu çalışmanın amacı, kullanılan girdilerin ve üretim süreçlerinin üretim hattındaki etkinliğe ve verimliliğe etkisini genel ekipman verimliliği yöntemi ile üretim hattından veriler toplayarak tespit etmektir. Toplanan veriler kullanılarak bir polo yaka t-shirt hattının öncelikle genel ve makineler -düz, overlok, otomat, ütü (el işleri dahil)- bazında kullanılabilirlik, performans, kalite ve OEE değerleri hesaplanmış ve bant verimliliği hakkında değerlendirmeler yapılmıştır.

\section{Materyal ve Metot}

\subsection{Materyal}

Çalışmanın materyalini bir konfeksiyon üretim fabrikasının polo yaka t-shirt üretim bandı oluşturmaktadır. Gerekli verilerin toplanabilmesi için üretim band 4 hafta süre ile izlenmiş ve tüm ilgili veriler kayıt edilmiştir. Söz konusu üretim bandında 39 adet mavi yakalı, 2 adet beyaz yakalı personel ve toplamda 36 adet makine görev yapmaktadır. Makinelerin 17 tanesi düz dikiş makinesi (DDM), 11 tanesi zincir dikiş makinesi (ZDM), 3 tanesi otomat ve 5 tanesi ütüdür. Üretim departmanı günde 2 vardiya ve her bir vardiya planlı duruşlar hariç (öğle arası 30 dakika ve 2 adet 15 'er dakikalık çay molası ile toplamda 1 saat) 8 saat halinde çalışmaktadır. Verilerin elde edildiği polo t-shirt ait işlem ve makine türleri ile üretim zamanları Tablo.1 de gösterilmektedir. 
Tablo 1. Polo Yaka T-Shirt Üretiminin Işslem Basamakları

\begin{tabular}{|c|c|c|c|}
\hline İşlem No & Operasyon & Makine Türü & İşlem süresi (dk) \\
\hline 1 & Ön Parça Etek Kıvırma & Reçme Dikiş Makinesi & 0.52 \\
\hline 2 & Pata Tela Yapıştırma & Ütü & 0.50 \\
\hline 3 & Pat Kıvırma Ütüsü & Ütü & 0.45 \\
\hline 4 & Düğme Patının İç Dikişi & Düz Dikiş Makinesi & 0.77 \\
\hline 5 & İlik Patına Tela Yapıștırma & Ütü & 0.45 \\
\hline 6 & İlik Patı Kıvırma Ütüsü & Ütü & 0.40 \\
\hline 7 & İlik Patı İç Dikişi & Düz Dikiş Makinesi & 0.65 \\
\hline 8 & Arka Parça Etek Kıvırma & Reçme Dikiş Makinesi & 0.52 \\
\hline 9 & Kol Ağzına Ribana Takma & 4 İplik Overlok Makinesi & 0.65 \\
\hline 10 & Kol Altı Birleştirme & 4 İplik Overlok Makinesi & 0.73 \\
\hline 11 & Kol Çevirme & El ile & 0.36 \\
\hline 12 & Omuz Birleştirme & 4 İplik Overlok Makinesi & 0.87 \\
\hline 13 & Omuz Bandını Kesme & El ile & 0.35 \\
\hline 14 & Omuz Çıması & Düz Dikiş Makinesi & 0.77 \\
\hline 15 & Yaka Takma & 4 İplik Overlok Makinesi & 1.38 \\
\hline 16 & Ön Patı Çevirme & El ile & 0.35 \\
\hline 17 & Pat Ucu Kesme & El ile & 0.28 \\
\hline 18 & Yaka Bastırma & Düz Dikiş Makinesi & 0.80 \\
\hline 19 & Pat Çıması & Düz Dikiş Makinesi & 0.98 \\
\hline 20 & Üst Pat Kenar Çıması & Düz Dikiş Makinesi & 0.73 \\
\hline 21 & Alt Pat Bastırma & Düz Dikiș Makinesi & 0.62 \\
\hline 22 & Alt Pat Kenar Çıması & Düz Dikiş Makinesi & 0.73 \\
\hline 23 & Pat Ucu İç Dikişi & Düz Dikiş Makinesi & 0.65 \\
\hline 24 & Pat Ucu Üst Çıma & Düz Dikiş Makinesi & 0.65 \\
\hline 25 & Pat Ucu İç Overlok & 4 İplik Overlok Makinesi & 0.27 \\
\hline 26 & Yan Kapama & 4 İplik Overlok Makinesi & 1.38 \\
\hline 27 & Yırtmaç Yapma & Düz Dikiş Makinesi & 1.50 \\
\hline 28 & Kol Takma & 4 İplik Overlok Makinesi & 1.18 \\
\hline 29 & İlik Açma (2 adet) & İlik Makinesi & 0.80 \\
\hline 30 & İç-Diş Çevirme & El ile & 0.33 \\
\hline 31 & Düğme Yeri İşaretleme (2 adet) & El ile & 0.26 \\
\hline 32 & Düğme Dikme (2 adet) & Düğme Makinesi & 0.60 \\
\hline 33 & Etiket Dikme & Düz Dikiş Makinesi & 0.65 \\
\hline 34 & Ürün Kontrolü & El ile & 1.50 \\
\hline 35 & İplik Temizleme & El ile & 2.00 \\
\hline 36 & Ütü-Paket & Ütü-El ile & 2.50 \\
\hline \multicolumn{3}{|c|}{ Toplam } & 28.13 \\
\hline
\end{tabular}

\subsection{Metot}

OEE yöntemi 3 farklı ölçüm kriterinin harmanlanmasıyla oluşmaktadır. Bu kriterler, "Kullanılabilirlik", "Performans" ve "Kalite"dir. Bir makinenin, bir üretim bandının veya bir operatörün OEE hesaplamasının yapılmasında aşağıda gösterilen formül [1] kullanılmaktadır [12], [13], [14], [15].

$\mathrm{OEE}=$ Kullanılabilirlik $\mathrm{x}$ Performans $\mathrm{x}$ Kalite

Kullanılabilirlik, bir işletmede bulunan makine ve teçhizatlar herhangi bir duraksama olmadan müşterinin ödemeyi kabul ettiği değeri üretme işini yerine getirmesi olarak tanımlanmaktadır. $\mathrm{Bu}$ tanıma bağlı olarak bir aktivitenin kullanılabilirlik ölçümünün yapılmasında aşağıdaki formül (2) kullanılmaktadır [12], [13], [14], [15].
Kullanılabilirlik $=\frac{\text { Gerçek Üretim Süresi }}{\text { Planlanmış Üretim Süresi }} \times 100$

[2]

Performans, incelenen aktivitenin ne kadar hızda kaç adet üretildiğinin oranlanması ile elde edilen bir değerdir. Performans hız kayıplarını göz önünde bulundurur. $\mathrm{Bu}$ değer aşağıdaki formül (3) kullanılarak hesaplanır [12], [13], [14], [15].

Performans $=$

Standart Birim Süre $x$ Üretim Miktarl

Planlanmıș Üretim Süresi-Plansız Duruşlar $x 100$

Kalite, kalite standartlarını karşılamayan ve/veya tekrar işleme (rework/rpt) gerektiren üretilmiş parçaları göz önünde bulundurarak, işlem gerektirmeyen hatasız ürün olarak tanımlanan parçaların sayısına oranlanarak (4) numaralı formül yardımıyla hesaplanmaktadır [12], [13], [14], [15]. 


$$
\text { Kalite }=\frac{\text { Kaliteli Ürün }}{\text { Üretim Miktarl }} \times 100
$$

Genel ekipman verimliliğinin dünyada kabul görmüş ve dünya klasmanı adı verilmiş değerleri bulunmaktadır. Bu değerler kullanılabilirlik kriteri için \%90, performans kriteri için \%95, kalite kriteri için \%99,9 ve genel ekipman verimliliği değeri için ise $\% 85$ 'tir [13], [14], [15].

\section{Bulgular}

Polo yaka T-shirtünün üretildiği banttan elde edilen verileri oluşturan, haftalık planlanan ve gerçekleşen üretim süresi, makine türlerinin ortalama çevrim zamanları, bantta gerçekleşen planlı ve plansız duruşlar, haftalık üretim adetleri ile üretilen kusurlu ve kaliteli ürün sayıları Tablo 2' de ayrıntılı bir şekilde verilmiştir. Tablo 1'de verilen üretim işlemleri ve sürelerine göre düz dikiş makinelerinin gerçekleştirdiği operasyonlarının çevrim sürelerinin ortalamasının $0,79 \mathrm{dk}$, zincir dikiş makinelerinin 0,83 $\mathrm{dk}$, otomatların $0,70 \mathrm{dk}$ ve ütü işlemlerinin (el işçilikleri dahil) $0,75 \mathrm{dk}$ olarak hesaplanmıştır. yapılmıştır. Üretim bandında yer alan makinerler bazında ayrı ayrı olarak ve bandın tümüne ait ait kullanılabilirlik, performans ve kalite değerleri ile bunlardan elde edilen OEE değerleri aşağıdaki tabloda gösterilmiştir (Tablo 3). Tablo 3. de yer alan kullanılabilirlik değerleri incelendiğinde 2 . hafta otomat $(\% 88$. 90) ve üçüncü hafta düz dikiş makine $(\% 89,65)$ değerleri dışında bütün haftalarda tüm makine türlerinde dünya klasman değerlerinin üzerinde sonuçlar elde edildiği görülmektedir. Kullanılabilirlik kriterinde dünya klasmanı altında kalan iki değerinde sınır değerler olduğu görülmektedir.

Performans kriteri incelendiğinde ise veri toplanan 4 hafta boyunca makine bazı dikkate alınarak hesaplanan değerlerin hiç biri dünya klasman rakamlarını yakalayamadığı görülmektedir. 4 haftalık performans değerleri arasında en düşük performans $\% 70,58$ değeri ile 2. hafta ütü grubunda aittir. En yüksek değerler ise 3 . hafta düz dikiş makinesi $(\% 91,99)$ ve zincir dikiş makinesi $(\% 90,94)$ gruplarında hesaplanmıştır. Ütü performans kriteri değerlerine bakıldığında haftalar arasında \%70,58 ile \%81,59 arasında değiştiği ve dünya klasmanının çok altında olduğu görülmektedir.

Tablo 2. Makine Türüne Göre Veriler

\begin{tabular}{|c|c|c|c|c|}
\hline $\begin{array}{c}\text { Makine } \\
\text { Türü }\end{array}$ & Hafta & $\begin{array}{l}\text { Planlanmış } \\
\text { Üretim } \\
\text { Süresi }\end{array}$ & $\begin{array}{l}\text { Gerçek } \\
\text { Üretim } \\
\text { Süresi }\end{array}$ & $\begin{array}{c}\text { Ort. } \\
\text { Çevrim } \\
\text { Zamanı (dk) }\end{array}$ \\
\hline \multirow{4}{*}{ 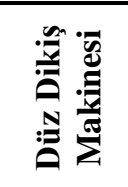 } & 1. hafta & \multirow{4}{*}{4800} & 4626 & \multirow{4}{*}{0,79} \\
\hline & 2. hafta & & 4652 & \\
\hline & 3. hafta & & 4303 & \\
\hline & 4. hafta & & 4569 & \\
\hline \multirow{4}{*}{ 污泀 } & 1. hafta & \multirow{4}{*}{4800} & 4664 & \multirow{4}{*}{0,83} \\
\hline & 2. hafta & & 4553 & \\
\hline & 3. hafta & & 4582 & \\
\hline & 4. hafta & & 4699 & \\
\hline \multirow{4}{*}{ 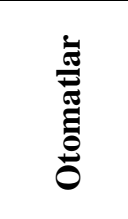 } & 1. hafta & \multirow{4}{*}{4800} & 4711 & \multirow{4}{*}{0,70} \\
\hline & 2. hafta & & 4267 & \\
\hline & 3. hafta & & 4727 & \\
\hline & 4. hafta & & 4683 & \\
\hline \multirow{4}{*}{ 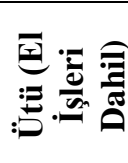 } & 1. hafta & \multirow{4}{*}{4800} & 4706 & \multirow{4}{*}{0,75} \\
\hline & 2. hafta & & 4782 & \\
\hline & 3. hafta & & 4613 & \\
\hline & 4. hafta & & 4731 & \\
\hline
\end{tabular}

Konfeksiyon üretimi çok çeşitli ve kısa süreli işlemlerden oluştuğundan, üretim zamanları, planlanan üretim adetleri ve hata oranları, operasyonun zorluğuna, opetatörün becerisine ve işlemin gerçekleştirildiği makinenin tipi, bakım durumu gibi birçok faktör üretimin kalitesinde ve verimliliğin ölçülmesinde etkili olmaktadır. Tablo 2.'de görülen işletme verilerinin farklılığ ve düzensizliği de bu durumu ortaya koyacak niteliktedir. Elde edilen 4 haftalık üretim bandının T-shirt üretim miktarları 4500 ile 5000 arasında değiştiği görülmektedir. Yine banttan çıkan kusurlu ürün miktarı haftalık olarak 90 ile 255 arasında değişim gösterirken plansız duruşlar $368 \mathrm{dk}$ ile $1050 \mathrm{dk}$ arasında değişim göstermiştir.

Gerçekleştirilen incelemeler sonucunda, elde edilen verilerin [2-4] numaralı formüllerle kullanılması sonucunda hafta hafta makine türüne göre ve genel bant değerlendirmeleri

\begin{tabular}{|c|c|c|c|}
\hline $\begin{array}{c}\text { Plansız } \\
\text { Duruşlar }\end{array}$ & $\begin{array}{l}\text { Üretim } \\
\text { Miktarı }\end{array}$ & $\begin{array}{c}\text { Kusurlu } \\
\text { Ürün }\end{array}$ & $\begin{array}{c}\text { Kaliteli } \\
\text { Ürün }\end{array}$ \\
\hline 174 & 4900 & 108 & 4792 \\
\hline 148 & 4500 & 50 & 4450 \\
\hline 497 & 5000 & 40 & 4960 \\
\hline 231 & 4780 & 52 & 4728 \\
\hline 136 & 4900 & 7 & 4893 \\
\hline 247 & 4500 & 33 & 4467 \\
\hline 218 & 5000 & 23 & 4977 \\
\hline 101 & 4780 & 27 & 4753 \\
\hline 89 & 4900 & 46 & 4854 \\
\hline 533 & 4500 & 43 & 4457 \\
\hline 73 & 5000 & 50 & 4950 \\
\hline 117 & 4780 & 23 & 4757 \\
\hline 94 & 4900 & 196 & 4704 \\
\hline 18 & 4500 & 14 & 4486 \\
\hline 187 & 5000 & 22 & 4978 \\
\hline 69 & 4780 & 23 & 4757 \\
\hline
\end{tabular}

İşletmeden elde edilen verilerle hesaplanan kalite değerlerine bakıldığında makine bazında kalite kriteri değerleri \%96 ile \%99,86 arasında değişmektedir. Kalite kriteri rakamları yüksek olmakla birlikte dünya klasman değeri olan \%99,9' a ulaşılamadığını göstermektedir. Kalite kriterine göre elde edilen en iyi sonuçlar zincir dikiş makinelerine aittir. Zincir dikiş makinelerinde kalite değerleri 2. hafta sonuçlarından elde edilen $\% 99,27$ ile ilk hafta sonuçlarından elde edilen \%99,86 değerleri arasında değişmektedir.

Polo yaka t-shirt üretim bandında yer alan tüm makinelerden elde edilen verilerle hesaplanan kullanılabilirlik, performans ve kalite değerlerinin 4 haftalık sonuçları incelendiğinde kullanılabilirlik değerleri $\% 79,69$ ile $\% 89,73$ arasında yer almaktadır. Performans değerleri \%102.15 ile \%87, 24, kalite değerleri ise $\% 97,38$ ile $\% 92.71$ arasında 
Tablo 3. Makine Türüne Göre Kullanılabilirlik, Performans, Kalite ve OEE Değerleri

\begin{tabular}{|c|c|c|c|c|}
\hline Klasman & Kullanılabilirlik & Performans & Kalite & OEE değeri \\
\hline Değeri & $\% 90$ & $\% 95$ & $\% 99,9$ & $\% 85$ \\
\hline Makine Türü & \multicolumn{4}{|c|}{ 1. Hafta } \\
\hline DDM & $\% 96,38$ & $\% 83,86$ & $\% 97,8$ & $\% 79,03$ \\
\hline ZDM & $\% 97,17$ & $\% 87,55$ & $\% 99,86$ & $\% 84,95$ \\
\hline Otomat & $\% 98,15$ & $\% 72,81$ & $\% 99,06$ & $\% 70,79$ \\
\hline Ütü & $\% 98,04$ & $\% 78,09$ & $\% 96,00$ & $\% 73,50$ \\
\hline \multirow[t]{2}{*}{ Tüm Bant } & $\% 89,73$ & $\% 88,91$ & $\% 92,71$ & $\% 73,96$ \\
\hline & \multicolumn{4}{|c|}{ 2. Hafta } \\
\hline DDM & $\% 96,92$ & $\% 76,58$ & $\% 98,89$ & $\% 73,39$ \\
\hline ZDM & $\% 94,85$ & $\% 82,36$ & $\% 99,27$ & $\% 77,55$ \\
\hline Otomat & $\% 88,90$ & $\% 73,82$ & $\% 99,04$ & $\% 65,00$ \\
\hline Ütü & $\% 99,63$ & $\% 70,58$ & $\% 99,69$ & $\% 70,09$ \\
\hline \multirow[t]{2}{*}{ Tüm Bant } & $\% 80,29$ & $\% 91,25$ & $\% 96,89$ & $\% 70,98$ \\
\hline & \multicolumn{4}{|c|}{ 3. Hafta } \\
\hline DDM & $\% 89,65$ & $\% 91,99$ & $\% 99,2$ & $\% 81,81$ \\
\hline ZDM & $\% 95,46$ & $\% 90,94$ & $\% 99,54$ & $\% 86,41$ \\
\hline Otomat & $\% 98,48$ & $\% 74,04$ & $\% 99,00$ & $\% 72,19$ \\
\hline Ütü & $\% 96,10$ & $\% 81,29$ & $\% 99,56$ & $\% 77,78$ \\
\hline \multirow[t]{2}{*}{ Tüm Bant } & $\% 79,69$ & $\% 102,15$ & $\% 97,30$ & $\% 79,21$ \\
\hline & \multicolumn{4}{|c|}{ 4. Hafta } \\
\hline DDM & $\% 95,19$ & $\% 82,82$ & $\% 98,91$ & $\% 77,98$ \\
\hline ZDM & $\% 97,90$ & $\% 84,77$ & $\% 99,44$ & $\% 82,52$ \\
\hline Otomat & $\% 97,56$ & $\% 71,45$ & $\% 99,52$ & $\% 69,37$ \\
\hline Ütü & $\% 98,56$ & $\% 75,78$ & $\% 99,52$ & $\% 74,33$ \\
\hline Tüm Bant & $\% 89,21$ & $\% 87,24$ & $\% 97,38$ & $\% 75,79$ \\
\hline
\end{tabular}

değişmektedir. 4 haftalık inceleme boyunca tüm banta ait kulanılabilirlik, performans ve kalite kriterleri sonuçları arasında sadece 3. haftanın tüm bant performans değeri dünya klasman değerinin üzerine çıkmıştır.

\section{Sonuç ve Tartışma}

Genel ekipman verimliliği, ekipman verimliliğinin ve etkinliğin artırılması amaciyla uygulanan, takibi ve uygulaması kolay olduğundan sıkça tercih edilen önemli yöntemlerden biridir. Genel ekipman verimliliğinde, işletme verimliliği, işletme performansı ve kalite açısından etkin rol almaktadırlar. İşletmenin eksiklerinin farkına varılarak analiz edilmesi, iyileştirilmesi ve başarılı olduğu alanlardaki devamlılığın etkin bir şekilde sürdürülmesi, bununla birlikte hedeflenen amaçlara ulaşılabilmesi açısından sağlıklı veriler sunmaktadır.

$\mathrm{Bu}$ araştırma ile konfeksiyon sektöründe polo yaka t-shirt üretimi yapan bir işletmenin makine bazında ve genel ekipman verimliliğinin ne düzeyde olduğu ortaya konmaya çalışılmıştır. Bunun için işletmeden 4 hafta boyunca toplanan veriler ile gerekli hesaplamalar yapılmıştır. Araştırma sonuçları veri toplanan bantın genel ekipman verimliliğinin $\% 70,98$ ile $\% 79,21$ değerleri arasında yer alarak $\% 85$ olan dünya klasman değerine 4 hafta boyunca ulaşılamadığını göstermektedir. İşletme genel ekipman verimliliğ̣i hesaplamalarına bakıldığında kullanılabilirlik kriterinin iki hafta dünya klasman değerinin hemen altında kaldığı, iki hafta da ise \%10-11 düşük değerdedir. Makineler arasında karşılaş̧ırma yapıldığında değerlerin dengeli ve birbirine yakın düzeyde olduğu görülmektedir. Performans değerleri ise 3 . hafta performans değerinin $\% 7,5$ dünya klasman değerlerinden yüksek, diğer haftalarda ise \%3,94 ile \%8,16 arasında daha düşük değerdedir. Ancak performans değeri makine bazında incelendiğinde aşağıdaki tablo oluşmaktadır.
Tablo 4. Makine Bazında OEE Değerleri

\begin{tabular}{|l|c|}
\hline Dünya Klasman Değeri & $\mathbf{8 5 \%}$ \\
\hline & 4 Hafta Ortalama OEE değeri \\
\hline Düz Dikiş Makinesi & $78.01 \%$ \\
\hline Zincir Dikiş Makinesi & $82.85 \%$ \\
\hline Otomat & $69.33 \%$ \\
\hline Ütü & $73.12 \%$ \\
\hline
\end{tabular}

$\mathrm{Bu}$ tabloya göre dünya klasman değerine sadece zincir dikiş makinesi ortalaması yaklaşırken, diğer makinelerin ortalamaları dünya klasman değerinin oldukça altında kalmıştır.

Dünya klasman değerleri ile bantın kalite kriteri değerleri incelendiğinde ise ilk hafta $\% 7,19$, diğer haftalarda da $\% 2,52$ $\% 3,01$ arasında düşük olduğu görülmektedir. Kullanabilirlik, performans ve kalite kriterlerindeki düşük değerler bantın genel ekipman verimliliğinde etkisini göstermiş ve bantın genel ekipman verimlilik değerlerinin düşmesine sebep olmuştur. Tüm ekipman verimliliği değerleri inceleme haftaları süresince dünya klasman değerinden $\% 6,81$ ile $\% 16,49$ düşük değerde hesaplanmıştır. 1. ve 3. haftalarda zincir dikiş makinelerinin genel ekipman verimliliği dünya kalsman değerini yakalamış olmasına rağmen diğer grupların verimlilik düşüklükleri tüm bant değeri üzerinde daha çok etkili olmuştur. $\mathrm{Bu}$ da sorunun kaynağına ulaşmak için bant verimliliğinin yanı sıra makine türlerine göre de verimlilik hesaplamalarının gerekliliğini ortaya koymuştur.

Konfeksiyon işletmeleri gibi özellikle hala emek yoğun yapısını koruyan işletmelerde ekipman verimliliği çok yönlü değerlendirilmeli ve verim düşüklüklerinin kaynağı iyi analiz edilmelidir. Düşük verimliliğin sebebi kullanılan makine, işi yapan operatör ve işin niteliği olabilmektedir. Gelecek çalışmalarda işletmedeki plansız duruşların, oluşan hataların 895 
dolayısıyla verim düşüklüklerinin sebebi araştırılacak, toplam üretken bakım, kaizen gibi yalın üretim teknikleri ile iyileştirmeler yapılarak mevcut durum ile değişimler analiz edilecektir.

\section{Kaynakça}

[1] Akal Z., (1992). “İmalatçı Kamu Kuruluşlarında İşletmeler Aras1 Toplam Performans, Verimlilik, Karlılık ve Maliyet Karşılaştırmaları", Ankara: MPM Yayınları.

[2] Güleç K., (1991). "Verimliliğin Arttırılmasında Yeni Gelişen Teknolojilerin Etkileri” Verimlilik Dergisi, Ankara: MPM Yayınlar1, s. 161-168.

[3] Kemahlı H., (2012). "OEE Genel Ekipman Verimliliğii", http://projesis.blogspot.com/2012/05/oee-genel-ekipmanetkinligi.html.

[4] Karim R., Rahman C. M. (2012). A performance analysis of OEE \& improvement potential at a selected apparel industry. In Proceedings of the 6th International Mechanical Engineering Conference\& 14th Annual Paper Meet (6IMECand14APM) (pp. 28-29).

[5] Senthilkumar B., Thavaraj H. S., (2014). An Evaluation of TPM Implementation in Clothing Industry in India-a Lean Philosophy Based Approach. International Journal Of Industrial Engineering \& Technology (IJIET), 4(6), 11-18.

[6] Binti A. N. A., Garza-Reyes J. A., Kumar V., Antony J., Rocha-Lona L. (2016). An analysis of managerial factors affecting the implementation and use of overall equipment effectiveness. International Journal of Production Research, 54(15), 4430-4447.

[7] Sivakumar, A., Prakash, S. D., \& Navaneethakrishnan, P. (2015). Dynamic Risk Identification Using Fuzzy Failure Mode Effect Analysis in Fabric Process Industries: A Research Article as Management Perspective. International Journal of Mathematical and Computational Sciences, 9(1), 276-280.

[8] Tomar S., Bhuneriya A. K. (2016). Analysis of OEE for TPM implementation: case study. Int J Bus Quant Econ Appl Manag Res, 2(8), 89-99.

[9] Ahmad N., Hossen J., Ali S. M. (2018). Improvement of overall equipment efficiency of ring frame through total productive maintenance: a textile case. The International Journal Of Advanced Manufacturing Technology,94(1), 239-256.

[10] Shakil S. I., Parvez, M. (2018). Application of lean manufacturing in a sewing line for improving Overall Equipment Effectiveness (OEE). American Journal of Industrial and Business Management, 8(9), 1951-1971.

[11] Yazdi G. P., Azizi, A., Hashemipour, M. (2018). An empirical investigation of the relationship between overall equipment efficiency (OEE) and manufacturing sustainability in industry 4.0 with time study approach. Sustainability, 10(9), 3031.

[12] Muchiri P., Pintelon L. (2008). Performance measurement using overall equipment effectiveness (OEE): literature review and practical application discussion. International Journal Of Production Research, 46(13), 3517-3535.

[13] Nayak E. A., Kumar V. M., Naidu G. S., Shankar V., (2013). Evaluation of OEE in a continuous process industry on an insulation line in a cable manufacturing unit. International Journal of Innovative Research in Science, Engineering and Technology, 2(5).
[14] Jonsson P., Lesshammar M., (1999). Evaluation and improvement of manufacturing performance measurement systems the role of OEE. International Journal of Operations \& Production Management. Vol. 19 No. 1, pp. 55-78.

[15] Gupta A. K., Garg R. K. (2012). OEE improvement by TPM implementation: a case study. International Journal of IT, Engineering and Applied Sciences Research, 1(1), 115124. 